\title{
Structural Heart Diseases during Pregnancy: Part 1-Valvular Heart Diseases
}

\author{
Amar N. Patnaik ${ }^{1}$ \\ ${ }^{1}$ Department of Cardiology, Star Hospitals, Hyderabad, \\ Telangana, India
}

Indian J Cardiovasc Dis Women-WINCARS 2018;3:108-114

\begin{abstract}
Address for correspondence Amar N. Patnaik, MD, DM, FSCAI, FACC, Department of Cardiology, Star Hospitals, 8-2-594/B, Road Number 10, Banjara Hills, Hyderabad, Telangana 500034, India (e-mail: anpatnaik@yahoo.com).
\end{abstract}

Abstract

Keywords

- cardiac disease

- pregnancy

- structural heart diseases
It is estimated that about 3\% pregnancies can have cardiac disease. There is wide variation in the spectrum of heart diseases. Pregnant women in India and other developing countries continue to show high prevalence of rheumatic heart disease (RHD). Pre-conception counseling based on a good echocardiographic evaluation is the most cost-effective method to prevent morbidity and mortality due to valvular heart disease. With advances in medical science, many with valvular heart disease are living to adulthood and undergoing successful pregnancy. Symptoms of a pregnant woman with a valvular disease depend on the altered hemodynamics of the specific valvular lesion in combination with the physiologic changes inherent to the pregnancy itself. A good echocardiographic evaluation of all pregnant women on their first visit to an obstetrician's office is an effective strategy to prevent morbidity and mortality from valvular heart diseases. In general, the regurgitant lesions are well tolerated during pregnancy and labor. Asymptomatic but significant valve lesions can be decompensated by many factors. Severely stenosed mitral and, sometimes, aortic valve may have to be balloon-dilated by trained experts in midterm taking due care to avoid excess radiation. Valve surgery is rarely performed in absence of any other safer option. A multidisciplinary team approach is required to manage a pregnant woman with significant cardiac lesion with high-risk features and patients having mechanical valves that require continuous anticoagulation.

\section{Introduction}

Pregnancy and peripartum periods in a woman with heart disease can be a vulnerable phase in the natural history of many valvular heart diseases. With advances in medical science, many with valvular heart disease are living to adulthood and undergoing pregnancy. Symptoms of a pregnant woman with a valvular disease depend on the altered hemodynamics of the specific valvular lesion in combination with the physiologic changes inherent to the pregnancy itself. Either stenosis, regurgitation, or both can occur in one or more of the four major valves. Ventricular function may be preserved or affected to varying degrees that influence the symptoms, treatment, and prognosis. The following review focuses on these problems and their management principles based on recent recommendations of world bodies such as the American Heart Association (AHA), American College of Cardiology (ACC), and European Society of Cardiology (ESC).

\section{Hemodynamics of Normal Pregnancy}

Cardiac output (COP) rises by approximately 40 to $50 \%$ due to marked increase in stroke volume and a modest rise in heart rate, especially in later weeks of pregnancy. The rise in COP is rapid in the first trimester but plateaus in the second and third trimesters. Simultaneously, because of the hormonal changes of pregnancy, the systemic vascular resistance decreases by end of the second trimester and slowly increases by term. By end of the first trimester, there can be 
physiologic anemia and expansion of plasma volume. These can lead to an increase in gradients across valves ( - Table $\mathbf{1}$ ). Pregnancy and early postpartum periods are hypercoagulable states that have a potential to affect the functioning of prosthetic valves.

During active uterine contraction, as much as $500 \mathrm{~mL}$ blood can be transfused from placental circulation to the maternal systemic circulation. There can be acute rise in COP by $30 \%$ during the first stage of labor and approximately $80 \%$ in the immediate postpartum stage. This sharp increase is maintained for the first 24 hours of delivery. However, the hemodynamic changes during labor and postpartum periods are also influenced by the type of delivery, use of spinal/epidural anesthetics, and amount of blood loss.

\section{Structural and Functional Changes in Heart in Pregnancy}

In an Indian study, the structural and functional changes in maternal heart during pregnancy were studied in 100 patients using standard echocardiographic (echo) methods. With advancing gestational age, there was an increase in left atrial (LA) diameter, left ventricular (LV) end-diastolic diameter, and interventricular septum (IVS) thickness. There was a gradual decrease in E-wave velocity, and E/A ratio increased during the second trimester and decreased during the third trimester. The E-wave deceleration time increased with gestational age. There was no statistically significant difference between IVS thickness and E/A ratio $(p=1.000)$. These reflect a subtle reduction in myocardial compliance, which could be a normal adaptive response. ${ }^{1}$

\section{Crux of the Problem}

It is estimated that about 3\% pregnancies can have cardiac disease. However, there is wide variation in the spectrum of heart diseases. In developed countries, the incidence of rheumatic heart disease (RHD) is on decline, but women in India and other developing countries continue to show high prevalence of RHD, especially in the child-bearing period (-Table 2).

Obstetricians in India are more likely to come across lone mitral stenosis (MS) or along with various degrees of mitral regurgitation (MR). Lone MR (rheumatic or mitral valve

Table 1 Structural and hemodynamic changes in normal pregnancy

\begin{tabular}{|l|l|l|l|l|}
\hline & Heart rate & SVR & COP & LV size \\
\hline $\begin{array}{l}\text { First } \\
\text { Trimester }\end{array}$ & $\uparrow$ & $\downarrow$ & $\uparrow$ & $\uparrow$ \\
\hline $\begin{array}{l}\text { Second } \\
\text { trimester }\end{array}$ & $\uparrow$ & $\downarrow$ & $\uparrow$ & $\uparrow$ \\
\hline $\begin{array}{l}\text { Third } \\
\text { trimester }\end{array}$ & $\uparrow$ & $\begin{array}{l}\downarrow \\
\text { Late rise }\end{array}$ & $\begin{array}{l}\uparrow \\
\text { Late drop }\end{array}$ & $\uparrow$ \\
\hline $\begin{array}{l}\text { Early } \\
\text { postpartum }\end{array}$ & $\downarrow$ & $\uparrow$ & $\downarrow$ & $\downarrow$ \\
\hline
\end{tabular}

Abbreviations: COP, cardiac output; LV, left ventricular; SVR, systemic vascular resistance. prolapse syndrome [MVPS]), lone aortic regurgitation (AR) with or without aortic stenosis (AS), and congenital pulmonary valve stenosis are also not uncommon. ${ }^{3}$ In the REMEDY (Rationale and design of a Global Rheumatic Heart Disease registry) study conducted in 12 countries in Asia (including India) and Africa that included all pregnant women with cardiac disease, $25 \%$ had valvular heart disease. In the same registry, it was observed that heart failure (HF) was present in $22 \%$ pregnant women with rheumatic valve disease. ${ }^{4}$

\section{Mitral Stenosis}

Mitral stenosis is invariably rheumatic in etiology and is the most common valve lesion in pregnant women in India. It is common to see that previously asymptomatic cases of moderate to severe MS become symptomatic during pregnancy. With tachycardia, the diastole is shortened, the pressure gradient across the diseased mitral valve increases, and there is increased pulmonary venous and arterial hypertension. Presence of atrial fibrillation accelerates these hemodynamic effects. Thus a pregnant woman with MS becomes increasingly symptomatic as she crosses the middle of the mid-trimester. These abnormalities can lead to maternal and fetal adverse outcomes, including fetal growth retardation, low birth weight, and premature birth. Complications such as pulmonary edema and arrhythmias can occur in $35 \%$ of the pregnancies in mothers with severe MS. Premature delivery can vary from $14 \%$ (mild MS) to $33 \%$ (severe MS). ${ }^{5}$ At the time of labor and immediately after the delivery due to auto-transfusion of blood, the maternal circulation can be flooded and precipitate pulmonary edema, the risk persisting even up to 24 to 72 hours after delivery. It is at this period the risk for maternal death is the highest. ${ }^{6}$

\section{Aortic Stenosis}

Lone aortic stenosis is more often nonrheumatic in etiology. It is common to have a congenital bicuspid aortic valve that develops valve stenosis and aortopathy or associated coarctation of the aorta (COA). With increasing severity, the maternal and fetal adverse effects increase. Hemodynamic comprise, HF (3-10\%), or arrhythmias (25\%) can occur maximum in the second and third trimesters or during labor and delivery. The incidence of fetal low birth weight and preterm births are also higher in presence of significant AS ( 25\%). Maternal mortality can be as high as $17 \%$ in presence of severe AS. However, ROPAC (Registry in Pregnancy and Cardiac Disease) was initiated in January 2008 by ESC working group on congenital and valvular heart disease. In this prospective study

Table 2 Incidence of cardiac lesions in pregnant women in India and the West ${ }^{2}$

\begin{tabular}{|l|l|l|}
\hline & West (\%) & India (\%) \\
\hline All CVD & $0.2-4$ & $0.5-1$ \\
\hline RHD & $10-15$ & $56-89$ \\
\hline $\begin{array}{l}\text { Congenital heart } \\
\text { disease }\end{array}$ & $75-82$ & $9-19$ \\
\hline
\end{tabular}

Abbreviations: CVD, cardiovascular disease; RHD, rheumatic heart disease. 
of 2,966 pregnant women, 96 had at least moderate AS. The mortality in them was zero. However, among symptomatic severe AS, there was increased incidence of HF and hospitalizations. Peak aortic gradient was the most important predictor for worse outcome. Maternal complications rose 2.8-fold and the fetal outcomes increased 7.6 times when the moderate AS became severe in this study. ${ }^{7,8}$

\section{Pulmonary Valve Stenosis}

Typically right-sided stenotic lesions including pulmonary valve stenosis are better tolerated than left-sided stenotic lesions. Very severe pulmonary stenosis (PS) can go into right ventricular failure despite medical treatment. It may be wiser to do balloon valvotomy in select cases.

\section{Regurgitant Lesions}

As the systemic vascular resistance (SVR) is decreased in pregnancy, the regurgitant lesions are better tolerated as long as the ventricular function is preserved. The volume overload in the second and third trimesters and acute increase in cardiac output in the first 2 to 3 days after delivery can bring out symptoms such as palpitations and breathlessness in presence of regurgitant lesions. Some patients may have atrial arrhythmias.

\section{Mechanical Heart Valves}

A chance to conduct a pre-conception counseling is the best thing in the care of patients with mechanical valves. The need for optimal anticoagulation during pregnancy and delivery must be explained to the patient and her family in detail. In those on high doses of warfarin, embryopathy, hemorrhage, and a fetal loss can occur at a rate of approximately 35\%. Warfarin easily crosses the placenta, resulting in significant levels in the fetus. This can result in threatened abortion, typical facial malformations (hypoplastic nose), and stippled epiphyses in more than $6 \%$ of children born to mothers treated with warfarin during the first trimester. Neonatal respiratory distress secondary to upper airway obstruction can occur in about onehalf of the patients. Exposure during the second and third trimesters seem to have an increased risk of structural anomalies in the central nervous system (such as microcephaly, hydrocephalus, agenesis of corpus callosum, and Dandy-Walker malformation) as well as eye anomalies (optic atrophy, microphthalmia, and Peter anomaly of eye). Other clinical findings of fetal warfarin syndrome (FWS) include scoliosis, significant developmental retardation, deafness, congenital heart disease (CHD), and seizures. ${ }^{9}$ For those on warfarin in doses $>5 \mathrm{mg} /$ day, recommended dose/drug modification must be performed. In patients with $>5 \mathrm{mg}$ of warfarin, switching to therapeutic doses of low-molecular-weight heparin (LMWH) with low-dose aspirin in the second and third trimesters with periodic monitoring of anti-XA is recommended. The goal is to have 0.8 to 1.2 $\mathrm{U} / \mathrm{mL}$ after 4 to 6 hours of the last dose. ${ }^{10,11}$

\section{Arrhythmias}

Valvular heart disease can precipitate supraventricular arrhythmias such as atrial fibrillation/flutter. Paroxysmal supraventricular arrhythmias can be terminated by vagal maneuvers or adenosine. If ventricular tachycardias occur, they can be reverted using synchronized cardioversion, which is generally safe. Chronic atrial fibrillation, especially with mitral stenosis, calls for chronic anticoagulation as the pregnancy period is more vulnerable for thromboembolic complication. Antiarrhythmic agents such as flecainide or sotalol may be used, if required.

\section{Risk Stratification}

A complete history and physical examination along with simple tests such as electrocardiogram (ECG) and two-dimensional (2D) echocardiography can immensely help in assessment of any cardiac disease in pre-conception counseling or the first antenatal checkup. Unfortunately most patients in India and the other developing countries are not aware of cardiac disease. They have cardiac disease for many years until seen and told by the general practitioner or the obstetrician during their first antenatal visit. When symptoms such as progressive dyspnea, orthopnea, nocturnal cough, hemoptysis, syncope, or chest pain are reported, suspect the possibility of cardiac disease. It is important to realize that there can be mistaken overdiagnosis of cardiac disease in pregnancy on clinical examination alone. The first heart sound can be loud because of increase in COP. It can be mistaken as S4 or as a systolic click. Loud P2 may be heard without pulmonary hypertension or an atrial septal defect. Physiologic third heart sound can be present due to increased blood volume, and systolic murmurs due to increased blood flow at the apex or left sternal border may also be appreciated. There can be mammary soufflé that can be mistaken for an organic murmur. ${ }^{12}$ Presence of marked edema, a fourth heart sound, diastolic murmurs, jugular venous pressure of $2 \mathrm{~cm}$, and a persistent tachycardia of 100 beats $/ \mathrm{min}$ should alert to the possibility of significant cardiac lesion. ${ }^{13}$

In pre-conception counseling, the patient and her family must be educated about the nature of the cardiac disease, possible complications, and available options to prevent the same. If the patient has no choice but to undergo a valve surgery, the cardiologist must explain about the relative merits and demerits of mechanical and bioprosthetic valves. The tissue valves are less thrombogenic and do not need anticoagulation if in sinus rhythm, but there is chance for degeneration in approximately 8 years requiring a redo-surgery. Pregnancy is best avoided in presence of severe pulmonary hypertension/Eisenmenger's syndrome, ventricular ejection fraction $<30 \%$, ventricular dysfunction with New York Heart Association (NYHA) III/IV symptoms, critical MS, symptomatic severe AS, Marfan's syndrome with ascending aortic diameter $>45 \mathrm{~mm}$, bicuspid aortic valve with aortic diameter $>50 \mathrm{~mm}$, native severe coronary artery disease (CAD), or prior postpartum cardiomyopathy with residual ventricular dysfunction.

There are three well-known risk scores available for stratifying pregnant women with a cardiac lesion (-Tables 3-5). Currently CARPREG (Cardiac Disease in Pregnancy) score is used widely, especially in presence of valvular heart disease. The ZAHARA (Zwangerschap bij vrouwen met een 
Aangeboren HARtAfwijking) score is best used when there is a congenital heart disease. The World Health Organization (WHO) classification is more elaborate and broad-based comprising almost all cardiac disorders that can be encountered in pregnancy

Modified WHO system for risk assessment of cardiac conditions in pregnancy: This classification has been validated and accepted by ESC guidelines. ${ }^{15}$

\section{Medical Management}

A good echo evaluation of all pregnant women on their first visit to an obstetrician's office is the most effective strategy to prevent morbidity and mortality from valvular heart diseases. If a significant lesion is found in echo examination in each trimester, the last one at around 32 weeks of gestation is desirable. Echo should include measurement of aortic diameter if bicuspid aortic valve or coarctation is present. If a mechanical valve is present, it requires careful assessment (

In general, regurgitant lesions are well tolerated during pregnancy and labor. Asymptomatic but significant valve lesions can decompensate by factors such as excess salt ingestion, undue exertion, anemia, hyperthyroidism, infections, systemic hypertension, or arrhythmias. Such precipitating factors have to be prevented if feasible or corrected in time if detected. The management includes anemia correction, heart rate control, and mild diuresis. Metoprolol, diltiazem, or propranolol are widely used agents for this end. Appropriate infective endocarditis prophylaxis is to be done. The drugs that can cause potential harm to the fetus during pregnancy have to be remembered by all physicians while treating patients with valvular disease ( - Table 6 ).

Infective endocarditis is fortunately a rare complication with a reported incidence of $0.006 \%$, but it has a very high maternal mortality (33\%) either due to HF or embolic event. Fetotoxic effects of antibiotics should be understood by all obstetricians and cardiologists. While antibiotics such as penicillin, ampicillin, amoxicillin, erythromycin, mezlocillin, and cephalosporins can be used at all trimesters, aminoglycosides, quinolones, and tetracyclines should be used only for vital indications. Adverse fetal risk cannot be excluded with vancomycin, imipenem, rifampicin, and teicoplanin. ${ }^{16}$

During labor, obstetricians should try to shorten the second stage and monitor the vitals closely. Avoid methyl ergotamine. Early use of effective epidural anesthesia is recommended for smooth labor. In high-risk cases, elective cesarean section (CS) will help in prevention of acute HF.

An invasive hemodynamic monitoring during labor should be considered in conditions such as unexplained or refractory pulmonary edema, HF or oliguria, intraoperative or intrapartum cardiovascular decompensation, critical AS $\left(<1 \mathrm{~cm}^{2}\right)$, or MS $\left(<1.5 \mathrm{~cm}^{2}\right)$, Eisenmenger's syndrome, NYHA class III or IV cardiac disease, peripartum or perioperative CAD, refractory pulmonary edema, or oliguria in the setting of severe pulmonary hypertension.

\section{Anticoagulation Management in a Patient with Mechanical Prosthetic Valve}

In patients having mechanical valves that require continuous anticoagulation, expert team-based management throughout the pregnancy is recommended. Compared with unfractionated heparins (UFHs) or LMWHs, valve thrombosis is lesser with warfarin. In most centers in India, it had been the standard practice to use UFHs before 12 weeks and after 36 weeks of gestation, while using warfarin in between to allow ease of administration at home. Some physicians prefer to substitute warfarin from 6th to 12th week when it is most risky for

Table 4 CARPREG risk score

\begin{tabular}{|l|l|}
\hline Risk factor & Score and risk of \\
1.Prior cardiac event/ & $0=5 \%$ risk \\
arrhythmia & $1=27 \%$ risk \\
2. NYHA > II or cyanosis & $>2=75 \%$ risk \\
$\begin{array}{l}\text { 3. Left heart obstruction } \\
\text { 4. Systemic ventricular } \\
\text { dysfunction }\end{array}$ & \\
(EF $<40 \%)$ & \\
\hline
\end{tabular}

Abbreviations: CARPREG, Cardiac Disease in Pregnancy; EF, ejection fraction; NYHA, New York Heart Association.

Table 3 ASOG $19922^{14}$ classified various cardiac lesions into groups based on the mortality risk

\begin{tabular}{|l|l|l|}
\hline Group & Mortality risk (\%) & Lesions \\
\hline 1 & $1-2$ (Minimal) & $\begin{array}{l}\text { ASD, VSD, PDA, pulmonary stenosis, tricuspid stenosis, } \\
\text { Corrected TOF, bioprosthetic mitral valve stenosis (class I/II) }\end{array}$ \\
\hline 2 & $5-15$ (Moderate) & $\begin{array}{l}\text { MS II/IV, aortic stenosis, coarctation of aorta without valve affection, uncor- } \\
\text { rected TOF, previous MI, Marfan's syndrome with normal aorta }\end{array}$ \\
\hline A & $\begin{array}{l}\text { Mitral stenosis with AF } \\
\text { Artificial valve }\end{array}$ \\
\hline B & $\begin{array}{l}\text { Pulmonary hypertension, coarctation of aorta with valve affection } \\
\text { Marfan's syndrome with aortic involvement }\end{array}$ \\
\hline 3 & $25-50$ (Major) &
\end{tabular}

Abbreviations: AF, atrial fibrillation; ASD, atrial septal defect; ASOG, American College of Obstetricians and Gynecologists; MI, myocardial infarction; MS, mitral stenosis; PDA, patent ductus arteriosus; TOF, tetralogy of Fallot; VSD, ventricular septal defect; cardiovascular disease; RHD, rheumatic heart disease. 
Table 5 Modified WHO system for risk assessment of cardiac conditions in pregnancy

\begin{tabular}{|c|c|}
\hline WHO class & Conditions included \\
\hline $\begin{array}{l}\text { I-Risk is like general } \\
\text { population }\end{array}$ & $\begin{array}{l}\text { Mild PS, MVP, PDA, repaired } \\
\text { ASD/VSD/PDA, anomalous } \\
\text { veins, isolated atrial/ventric- } \\
\text { ular ectopics }\end{array}$ \\
\hline $\begin{array}{l}\text { II-Small increased maternal } \\
\text { mortality and morbidity }\end{array}$ & $\begin{array}{l}\text { Unrepaired ASD/VSD; re- } \\
\text { paired TOF; most arrhyth- } \\
\text { mogenic disorders }\end{array}$ \\
\hline $\mathrm{II} / \mathrm{III}$ & $\begin{array}{l}\text { LVEF > 30\% but < 50\%, NYHA } \\
\text { I/II } \\
\text { HCM, nonsevere valve ste- } \\
\text { nosis, tissue valve, repaired } \\
\text { COA, Marfan's syndrome } \\
\text { without aortic dilatation; } \\
\text { bicuspid aortic valve with } \\
\text { aorta < } 45 \mathrm{~mm}\end{array}$ \\
\hline III-Significant increased risk & $\begin{array}{l}\text { Mechanical valve, system- } \\
\text { ic RV, Fontan circulation, } \\
\text { unrepaired cyanotic heart } \\
\text { disease and other complex } \\
\text { CHD, Marfan's syndrome } \\
\text { with aorta } 40-45 \mathrm{~mm} \text {, } \\
\text { bicuspid aortic valve with } \\
\text { aorta > 45-50 mm }\end{array}$ \\
\hline $\begin{array}{l}\text { IV-Pregnancy is contrain- } \\
\text { dicated. If not terminated, } \\
\text { extreme care required }\end{array}$ & $\begin{array}{l}\text { Pulmonary hypertension, } \\
\text { ventricular EF }<30 \%-N Y H A \\
\text { II-IV, severe AS or MS, } \\
\text { previous peripartum car- } \\
\text { diomyopathy with residual } \\
\text { LV impairment, Marfan's } \\
\text { syndrome with aorta > } 45 \\
\text { mm, bicuspid aortic valve } \\
\text { with aorta }>50 \text { mm, severe } \\
\text { COA }\end{array}$ \\
\hline
\end{tabular}

Abbreviations: AS, aortic stenosis; ASD, atrial septal defect; CHD, congenital heart disease; COA, coarctation of aorta; EF, ejection fraction; HCM, hypertrophic cardiomyopathy; LV, left ventricular; LVEF, left ventricular ejection fraction; MS, mitral stenosis; MVP, mitral valve prolapse; NYHA, New York Heart Association; PDA, patent ductus arteriosus; PS, pulmonary stenosis; TOF, tetralogy of Fallot; VSD, ventricular septal defect; WHO, World Health Organization.

embryopathy. While a patient is on warfarin, it is unsafe for vaginal delivery. It is advisable to shift from warfarin to LMWFs at 36 weeks of gestation. CS is to be offered if a woman goes into labor while on warfarin after administration of vitamin $\mathrm{K} 10$ mg intravenously over 20 to 60 minutes and sometimes there may be a need for use of fresh frozen plasma. Some centers monitor peak or trough levels of factor Xa to monitor the levels of enoxaparin. LMWHs have to be stopped 24 hours before induction of labor. Resumption of UFH can be at approximately 6 hours after vaginal delivery or 12 hours after CS. Warfarin can be resumed as soon as possible after delivery. ${ }^{17-19}$

\section{Cardiac Indications for Cesarean Section Delivery}

Patients with mild or moderate to severe MS without pulmonary hypertension can be allowed to try vaginal delivery,

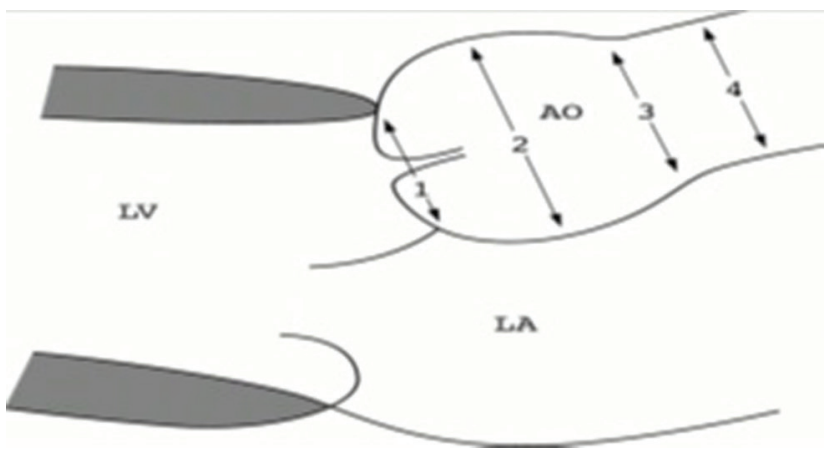

Fig. 1 Recommended echo measurements of aortic root and ascending aorta for bicuspid aortic valve: 1 , aortic annulus; 2 , root diameter; 3, sinotubular junction diameter; 4, ascending aorta diameter. AO, aorta; LA, left atrial; LV, left ventricular.

Table 6 Cardiac drugs with potential harm to fetus

\begin{tabular}{|l|l|}
\hline Drug & Possible effects \\
\hline ACE inhibitors/ARB & $\begin{array}{l}\text { Renal/tubular dysplasia, } \\
\text { IUGR, growth retardation, } \\
\text { ossification defects, lung } \\
\text { hypoplasia, contractures, } \\
\text { anemia }\end{array}$ \\
\hline Warfarin & $\begin{array}{l}\text { Hemorrhage, embryopathy, } \\
\text { fetal loss }\end{array}$ \\
\hline Statins & Congenital anomalies \\
\hline Spironolactone & $\begin{array}{l}\text { Antiandrogenic; cleft } \\
\text { abnormalities }\end{array}$ \\
\hline Hydralazine & Fetal tachycardia \\
\hline Diltiazem & ? teratogenic \\
\hline Furosemide & Oligohydramnios \\
\hline
\end{tabular}

Abbreviations: ACE, angiotensin-converting enzyme; ARB, angiotensin II receptor blocker; IUGR, intrauterine growth restriction.

but in presence of pulmonary hypertension or symptoms in class III or IV, CS is safer. In conditions such as dilated aortic root $>4 \mathrm{~cm}$ in COA, severe AS, acute severe HF, and history of recent myocardial infarction $(\mathrm{MI})$, use of warfarin within the past 2 weeks and a need for emergency valve replacement immediately after delivery call for an elective CS.

\section{Role of Percutaneous Methods}

Severe MS is poorly tolerated, and if the valve is suitable, percutaneous mitral valvotomy (PMV) is to be strongly considered. As exposure to radiation is an important concern. Proper assessment of valve morphology, performance by an expert with experience, adequate shielding of the mother's abdomen with lead sheet during the procedure (-Figs. 2, 3A, B and 4), and performing most of the steps involved without use of fluoroscopy will be desirable. When planned electively, 20th to 24th week is the best time for its performance as the organogenesis is complete and fetal thyroid is still inactive. Most of the popular cardiac centers in India with large volume of interventions can perform successful percutaneous balloon mitral valvotomy (PBMV) with least fluoroscopy time. At 
NIMS, Hyderabad, during 2009 to 2014, 50 PMV cases were done in pregnant women with $100 \%$ success rate. There were no complications or deaths. The mean fluoroscopic time was 4 minutes (unpublished data). Aortic and pulmonary valvoplasties are rarely performed unless the lesions are severe,

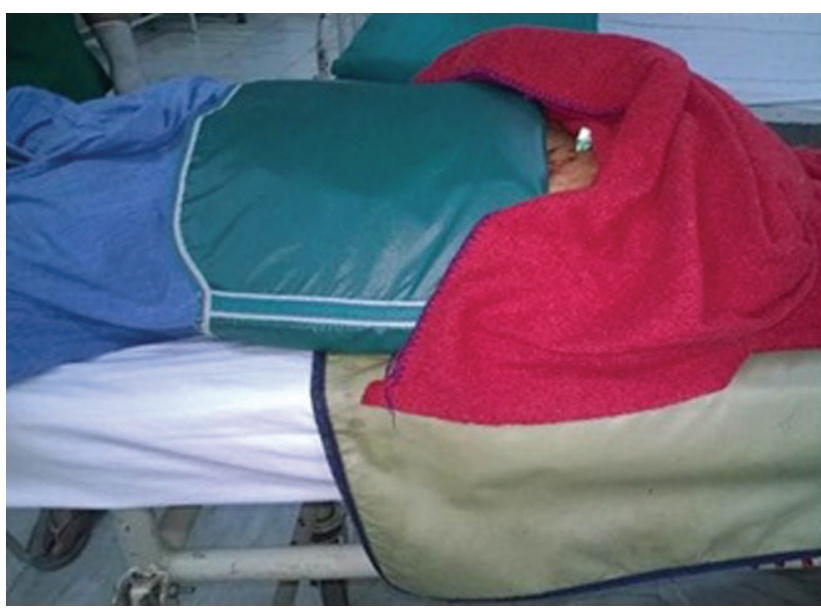

Fig. 2 Our practice of abdominal protection with lead aprons during percutaneous balloon mitral valvotomy in a pregnant woman.

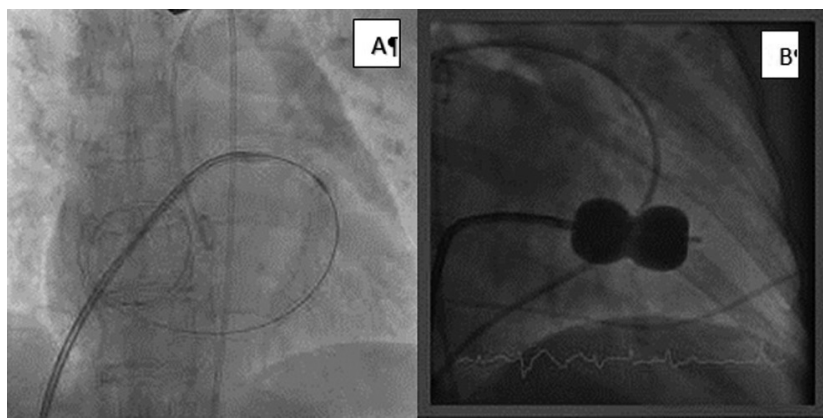

Fig. 3 (A, B) Images during percutaneous balloon mitral valvotomy in one of our cases.

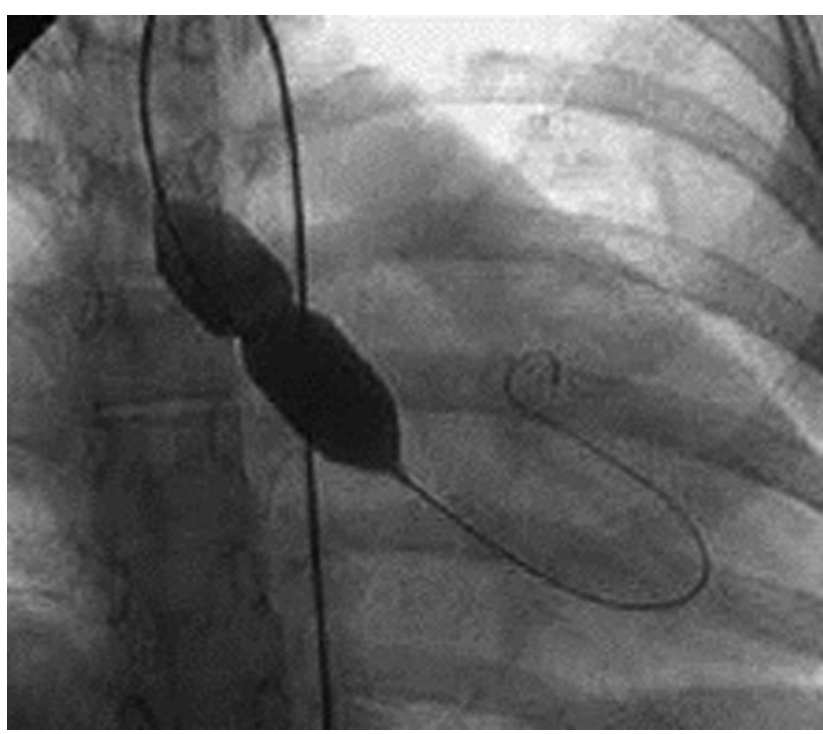

Fig. 4 Image during percutaneous balloon aortic valvotomy in one of our cases.
Table 7 Highlights from ESC 2018 recommendations on management of pregnancy with valvular heart disease

1. The pregnancy heart team consisting of multidisciplinary experts is to be created in all major hospitals for managing high-risk patients

2. Vaginal delivery is to be encouraged in most cases as far as feasible

3. Prophylactic antibiotics to prevent endocarditis is no longer recommended

4. In MS with MVA $<1 \mathrm{~cm}^{2}$ intervention is recommended before pregnancy

5. In MS if atrial fibrillation/LA thrombus or prior history of embolism, heparins or VKA recommended

6. In AS, intervene before pregnancy if LV dysfunction or symptoms are present; if detected while pregnant, do exercise testing if no symptoms are reported

7. For severe $A R / M R$, surgery is recommended before pregnancy if symptoms are present/LV dilated/dysfunctional

8. If pregnant with a mechanical valve, the heart team should be consulted

Abbreviations: AR, aortic regurgitation; AS, aortic stenosis; ESC, European Society of Cardiology; LA, left atrial; LV, left ventricular; MR, mitral regurgitation; MS, mitral stenosis; MVA, mitral valve area; VKA, vitamin $\mathrm{K}$ antagonist.

and the patient is symptomatic. They are not done as routine prophylactic measures. ${ }^{20-24}$

\section{Surgical Procedures}

Surgery during pregnancy is a team decision to be taken after much deliberation about the benefit and risk to the mother and fetus. With advances in anesthesia and surgical practice, the maternal mortality during cardiopulmonary bypass is now like that in nonpregnant women (9\%), but fetal mortality remains high, that is, 30 to $40 \%$. There is significant morbidity including late neurologic impairment in 3 to $6 \%$ of children. The best period for surgery is between the 13th and 28th week. If gestational age is 28 weeks or more, delivery before surgery is considered. Cardiopulmonary bypass time is minimized. MVR is reserved when PBMV cannot be performed, however, at an expense of 1.5 to $5 \%$ maternal mortality and fetal loss of approximately 16 to $33 \% .^{25}$

In the recently held ESC conference at Munich, the management of pregnancy with heart disease was discussed at length and their recommendations were published. The highlights are depicted in the - Table 7. In high-risk patients, management by "pregnancy heart team" is highly recommended in these guidelines. ${ }^{26}$

\section{Conclusion}

Pre-conception counseling based on a good echo evaluation is a very cost-effective method to prevent morbidity and mortality due to valvular heart disease during pregnancy and deliver. There is a need for a multidisciplinary team approach to manage a pregnant woman with significant cardiac lesion with high-risk features. 


\section{Conflict of Interest}

None.

\section{References}

1 Sunanda K, Sumalatha B, Ramakrishna J, Indrani G. Structural and functional changes in maternal heart during pregnancy: an echocardiographic study. Indian J Cardiovasc Dis Women 2017;2:72-76

2 Nanna M, Stergiopoulos K. Pregnancy complicated by valvular heart disease: an update. J Am Heart Assoc 2014;3(3):e000712

3 Soler-Soler J, Galve E. Worldwide perspective of valve disease. Heart 2000;83(6):721-725

4 Karthikeyan G, Zühlke L, Engel M, et al. Rationale and design of a Global Rheumatic Heart Disease registry: the REMEDY study. Am Heart J 2012;163(4):535-40.e1

5 Silversides CK, Colman JM, Sermer M, Siu SC. Cardiac risk in pregnant women with rheumatic mitral stenosis. Am J Cardiol 2003;91(11):1382-1385

6 Mann DL, Zipes DP, Libby P, Bonow RO, Braunwald E. Braunwald's Heart Disease: A Textbook of Cardiovascular Medicine. 10th ed. Philadelphia, PA: Elsevier/Saunders; 2015

7 Silversides CK, Colman JM, Sermer M, Farine D, Siu SC. Early and intermediate-term outcomes of pregnancy with congenital aortic stenosis. Am J Cardiol 2003;91(11):1386-1389

8 Orwat S, Diller GP, van Hagen IM, et al; ROPAC Investigators. Risk of pregnancy in moderate and severe aortic stenosis: from the multinational ROPAC registry. J Am Coll Cardiol 2016;68(16):1727-1737

9 Iturbe-Alessio I, Fonseca MC, Mutchinik O, Santos MA, Zajarías A, Salazar E. Risks of anticoagulant therapy in pregnant women with artificial heart valves. N Engl J Med 1986;315(22):1390-1393

10 Saeed CR, Frank JB, Pravin M, Aziz RH, Serasheini M, Dominique TG. A prospective trial showing the safety of adjusted-dose enoxaparin for thromboprophylaxis of pregnant women with mechanical prosthetic heart valves. Clin Appl Thromb Hemost 2011;17(4):313-319

11 Nishimura RA, Otto CM, Bonow RO, et al; American College of Cardiology/American Heart Association Task Force on Practice Guidelines. 2014 AHA/ACC guideline for the management of patients with valvular heart disease: executive summary: a report of the American College of Cardiology/American Heart Association Task Force on Practice Guidelines. J Am Coll Cardiol 2014;63(22):2438-2488

12 Cohen WR, August P. Textbook of Obstetric Medicine-Management of Medical Disorders in Pregnancy. 6th ed. New Delhi, India: Jaypee Brothers; 2015:131-153
13 Emmanuel Y, Thorne SA. Heart disease in pregnancy. Best Pract Res Clin Obstet Gynaecol 2015;29(5):579-597

14 Cardiac disease in pregnancy. ACOG technical bulletin number 168-June 1992. Int J Gynaecol Obstet 1993;41(3):298-306

15 Regitz-Zagrosek V, Blomstrom Lundqvist C, Borghi C, et al; European Society of Gynecology (ESG); Association for European Paediatric Cardiology (AEPC); German Society for Gender Medicine (DGesGM); ESC Committee for Practice Guidelines. ESC guidelines on the management of cardiovascular diseases during pregnancy. Eur Heart J 2011;32(24):3147-3197

16 Cox SM, Hankins GD, Leveno KJ, Cunningham FG. Bacterial endocarditis. A serious pregnancy complication. J Reprod Med 1988;33(7):671-674

17 Sillesen M, Hjortdal V, Vejlstrup N, Sørensen K. Pregnancy with prosthetic heart valves-30 years' nationwide experience in Denmark. Eur J Cardiothorac Surg 2011;40(2):448-454

18 van Hagen IM, Roos-Hesselink JW, Ruys TPE, et al; ROPAC Investigators and the EURObservational Research Programme (EORP) Team*. Pregnancy in women with a mechanical heart valve: data of the European Society of Cardiology Registry of Pregnancy and Cardiac Disease (ROPAC). Circulation 2015;132(2):132-142

19 Alshawabkeh L, Economy KE, Valente AM. Anticoagulation during pregnancy: evolving strategies with a focus on mechanical valves. J Am Coll Cardiol 2016;68(16):1804-1813

20 Ben Farhat M, Gamra H, Betbout F, et al. Percutaneous balloon mitral commissurotomy during pregnancy. Heart 1997;77(6):564-567

21 Salehi R, Aslanabadi N, Taghavi S, Pourafkari L, Imani S, Goldust M. Percutaneous balloon mitral valvotomy during pregnancy. Pak J Biol Sci 2013;16(4):198-200

22 de Souza JA, Martinez EE Jr, Ambrose JA, et al. Percutaneous balloon mitral valvuloplasty in comparison with open mitral valve commissurotomy for mitral stenosis during pregnancy. J Am Coll Cardiol 2001;37(3):900-903

23 McIvor RA. Percutaneous balloon aortic valvuloplasty during pregnancy. Int J Cardiol 1991;32(1):1-3

24 Galal MO, Jadoon S, Momenah TS. Pulmonary valvuloplasty in a pregnant woman using sole transthoracic echo guidance: technical considerations. Can J Cardiol 2015;31(1):103.e5-103.e7

25 Sutton SW, Duncan MA, Chase VA, Marce RJ, Meyers TP, Wood RE. Cardiopulmonary bypass and mitral valve replacement during pregnancy. Perfusion 2005;20(6):359-368 [PubMed: 16363322]

26 Regitz-Zagrosek V, Roos-Hesselink JW, Bauersachs J, et al; ESC Scientific Document Group. 2018 ESC guidelines for the management of cardiovascular diseases during pregnancy. Eur Heart J 2018;39(34):3165-3241 